\section{CARLOTA ERAN TODAS: LAS REPRESENTACIONES DE LA REINA LOCA EN EL CASTILLO}

THEY WERE ALL CARLOTA: REPRESENTATIONS OF THE MAD OUEEN IN THE CASTEL

La figura de la reina loca recluida en un The figure of de mad queen imprisoned in a castillo aparece en muchas representaciones castle appears frequently throughout western artísticas. Este hecho, puesto en relación con culture. Cultural representations have great el de que las imágenes gozan de un poder power in the creation of widely held beliefs. excepcional en el proceso de transmisión de As western society has always tried to control creencias, explica que una sociedad como la women, thus it has created cultural artefacts occidental, en la que se ha buscado siempre illustrating the repression of women.

controlar a las mujeres, haya creado una serie

de artefactos culturale de artefactos culturales que muest
modelo de sometimiento femenino.

\section{KEY WORD:}

Imprisonment, image, control, madness.

\section{Palabras claves:}

Reclusión, imagen, control, locura.
En 1987 Fernando del Paso publicaba una novela de casi mil páginas que llevaba por título Noticias del Imperio en referencia al llamado Segundo Imperio Mexicano; una monarquía creada por Napoleón III en respuesta a la decisión de su presidente Benito Juárez de suspender los pagos de la deuda externa con Francia. El entonces emperador de los franceses, además de mandar un ejército de ocupación, va a enviar también a un príncipe de la Casa de Habsburgo, como heredero legítimo de los Reyes Católicos para que ocupe el trono. Por lo que en 1864 Maximiliano de Austria y su esposa Carlota de Bélgica desembarcarán en el puerto de Veracruz dispuestos a cumplir con su destino histórico.

Las noticias del título son las que, todavía en 1927, una octogenaria y alucinada Carlota cree seguir recibiendo de un imperio que había dejado de existir sesenta años antes, cuando los monarcas europeos, a quienes la emperatriz había acudido en 1867 a solicitar ayuda desde México, no hicieron nada para impedirlo, ni por evitar el fusilamiento de su marido a manos de las tropas republicanas de Juárez. Esa deserción de la causa mexicana por parte de los que en definitiva eran sus parientes precipitaría la locura de la reina, y como consecuencia de ello su posterior reclusión en un castillo propiedad de la familia real belga hasta el día de su muerte.

La novela, según unas palabras del autor a modo de introducción al comienzo, se basa en los hechos históricos que desencadenaron el triste final de la pareja imperial tras su llegada a México. A grandes rasgos, dichos acontecimientos son los mismos que podrían encontrarse en un manual de Historia general, como el de L. Navarro, Historia de las Américas (1991); pero también en un trabajo académico más específico sobre el tema, como el de J. Haslip, The Crown of Mexico. Maximilian and His Empress Carlota (1971); en una novela histórica, como la de M. de Grecia, La emperatriz del adiós (2000); e incluso convertido en materia de una lectura adaptada para estudiantes de lengua francesa, como la de B. Job, Charlotte l'impératrice d'autre-mer (2004). La verdad histórica de los hechos contenidos en Noticias del Imperio habría que buscarlos principalmente en los capítulos pares, en los cuales el autor mezcla varios tipos de géneros, desde el epistolar a la crónica periodística, para darle apariencia de objetividad a su relato. En cualquier caso, el grado de verisimilitud resultaría en este trabajo irrelevante, dado que lo que se pretende analizar es hasta qué punto, ese personaje de Carlota respondería al prototipo de la reina loca confinada en un castillo tan frecuente en nuestra cultura.

En principio parece que sí, pues es de esa manera, con la razón perturbada, como la protagonista de la novela se le muestra al lector en los restantes doce capítulos pares. Todos aparecen encabezados siempre con el título de "Castillo de Bouchout 1927", en alusión al lugar donde estuvo recluida y al año de su muerte. En todos ellos también, el retrato que se ofrece de la emperatriz es la de una anciana demente, cuya principal 
ocupación consiste en compartir con su marido difunto las noticias que cada mañana cree recibir de un mensajero del Imperio. Es en los contenidos de ese monólogo alucinado donde se aprecian de manera más evidente aquellos rasgos comunes que su ejecutante comparte con otras iguales que vivieron unas circunstancias parecidas, y es justamente con la suma de todas ellas como parece haberse llegado a la imagen arquetípica de la reina loca en su castillo.

La importancia que en algunas técnicas psicológicas como el psicodrama se le ha dado al trabajo con imágenes parece indicar que sería en éstas donde habría que buscar el origen y la fijación de ciertas creencias dentro de un grupo social determinado. Según J. Rojas- Bermúdez y G. Moyano en "Teoría y técnica de las imágenes sicodramáticas", el poder de la imagen no ha sido estudiado en profundidad debido en parte a que la tradición judeo-cristiana, se ha basado principalmente en lo verbal y “ha desvalorizado lo corporal y la imagen respecto a la palabra" (Rojas-Bermúdez, 2012: 15). Estos autores sostienen también que se ha establecido una dualidad entre ambas como si se tratara de elementos independientes; a la imagen se la habría considerado simplemente una huella de la percepción que acaba por desvanecerse o alterarse, por oposición al carácter inmutable de la palabra que se vincula con el mundo intelectual y de las ideas, aunque eidolon en griego e imago en latín signifiquen al mismo tiempo 'imagen e idea' (Rojas-Bermúdez, 2012: 16). Éste es el sentido con el que se empleará a partir de ahora la palabra imagen, como el de un término globalizador que incluye tanto los aspectos conceptuales como las distintas manifestaciones iconográficas que una creencia adopta en el seno de una cultura. En este caso, la de la reina loca encerrada en un castillo sería la forma iconográfica con la que en Occidente se ha representado en muchas ocasiones la idea de que es necesario ejercer un control sobre aquellos individuos que pudieran resultar peligrosos, bien por su condición de locos, bien por pertenecer al género femenino o bien por ambos motivos.

Para conseguir dicho propósito, los gobiernos y la Iglesia habrían contado desde antaño con una serie de establecimientos como las mazmorras o los conventos donde los mecanismos de restricción resultan bastante evidentes. Pero, a estas formas de control, denuncia Foucault, habría que sumarle otras más sutiles y fáciles de aplicar aparecidas en el siglo XIX como la filantropía y la higiene pública que se arrogan el derecho de "inmiscuirse en la vida de los otros, de su salud, de la alimentación, de la vivienda [...]. En nombre de la medicina se inspeccionaba como estaban instaladas las casas, pero también en su nombre se catalogaba a un loco, a un criminal, a un enfermo" (Foucault, 1978: 109-110).

En el caso de Carlota, la mazmorra o la torre de los castillos medievales han sido reemplazadas por los confortables salones de una residencia palaciega, pero, aun así, éstos continuarían conformado un espacio cerrado que limitará sus movimientos. En él, además, tendrá que someterse a una serie de controles enmascarados tras el ritual del aseo matinal en nombre del decoro y de la ciencia:

Despabílese, desperécese, su majestad, me dicen mis damas, y me traen mi faja, mis unas postizas, me traen mis medias de lana y mi dentadura, me traen mi peluca, y yo les digo que no ven que está muy oscuro, $[\ldots]$ las perras, como si no supiera que están siempre a la espera de sorprenderme para lanzarse sobre mí y llevarme a la tina y bañarme a la fuerza, y la fuerza ponerme ungüentos y perfumes y ropa limpia (del Paso, 1987: 321-323).

En esa escena se nos presenta a una Carlota casi desdibujada saliendo del sueño parece que son las camareras quienes le dan forma al colocarle las uñas, la dentadura, la peluca y la faja para sujetarle las carnes. La necesidad que como se evidencia en este pasaje tiene la protagonista de sus carceleras podría ponerse en relación con los conceptos de sujetivacion y desujetivación en el sentido que los utiliza Judith Butler (2001), para quien el sometimiento al poder es paradójico en tanto que ejerce una presión en el sujeto desde fuera y lo subordina relegándole a un orden inferior, pero también es algo que lo forma y del que depende para su existencia. El sometimiento, consiste pues, "en esa dependencia fundamental ante un discurso que no hemos elegido, pero que paradójicamente, inicia y sustenta nuestra existencia" (Butler, 2001: 12). La sujeción, del verbo sujetar, sería el proceso por el que Carlota y otras mujeres sometidas aceptan el control que se ejerce sobre ellas y se transforman en personas sumisas, con lo cual se convierten a su vez en sujeto en el sentido de que adquieren una identidad propia.

Como se va observando, la imagen de Carlota tiene la facultad de remitirnos a un prototipo reconocible $\mathrm{y}$, al mismo tiempo, la de desvelarnos ciertos aspectos que sin una mirada atenta pasarían desapercibidos. Es probable que ni siquiera su autor fuera consciente de que al contar la historia de una reina loca los estuviera incluyendo, pues cabe pensar que el proceso que los novelistas siguen a la hora de crear sus personajes sea semejante al de los pacientes de una consulta sicodramática cuando, a instancia del terapeuta, éstos tienen que construir la imagen de una pesadilla o de una obsesión para la exploración de su significado. Es decir, tanto uno como otro utilizarán los elementos culturales de los que dispongan a su alcance con el fin de convertir unos conceptos mentales difusos en una forma visual o en un motivo literario. En la terapia, al trabajar sobre la imagen conjuntamente con su creador, el psicólogo tiene la posibilidad de que su paciente le explique qué ha tratado de representar, "a qué corresponden sus detalles e interrelaciones, los significados de ciertas partes y el código utilizado para expresarse" (Rojas-Bermúdez, 1977: 140). En el caso de la novela que nos ocupa, la reflexión psicológica que tiene lugar en una consulta será sustituida por un análisis 
literario, pero este permitirá igualmente la objetivación de ciertos aspectos del personaje de Carlota que de otro modo pasarían desapercibidos por ser sumamente difusos.

La imagen, en su doble sentido iconográfico y conceptual, de una mujer de sangre real, loca o cuerda, confinada en un castillo, con independencia de los mensajes que de manera sutil pueda llevar asociados, parece formar parte de la iconografía de Occidente, y tiene el poder de excitar todavía hoy nuestra fantasía cuando llegan noticias de Oriente, como la aparecida recientemente en la prensa de que dos hijas del rey de Arabia Saudí aseguraban llevar trece años cautivas en uno de los palacios de su padre (El País, Madrid, 10/3/2014). Un listado somero con algunas de estas ilustres prisionera podría incluir, además de las referidas princesas saudíes, Jawaher y Sahar; a Dánae, hija del rey de Argos (García Gual, 1994); a Santa Bárbara, hija del rey Dióscoro de Nicomedia (Vorágine de la, 1997); a la real o ficticia Genoveva de Brabante (Smichd, 1930); a Isabel de Portugal (Rodríguez, 2004) y a su nieta Juana la Loca en Tordesillas (Gómez, 2008); a Isabel I de Inglaterra durante un tiempo en la Torre de Londres, y a su prima María de Escocia hasta su muerte (Starkey, 2001). Todas ellas se habrían visto sometidas a lo que Foucault, según Butler, denomina 'el cerco y la invasión completa del cuerpo por las prácticas significantes de prisión', entre las que cita "la inspección, la confesión, la regularización y normalización de los movimientos y gestos corporales" con los que el poder ha tratado de conseguir unos fines determinados siempre (Butler, 2001: 97). Ello explicaría que, en el caso de Juana la Loca, una de las locas por antonomasia, los historiadores no se hayan puesto de acuerdo todavía en si de verdad lo estaba o, si, por el contrario, su confinamiento habría obedecido a otras causas.

Si aceptamos que la imagen de una reina enclaustrada forma parte de los mecanismos difusos de control que los sistemas sociales utilizan para asentar la idea de la necesidad de aplicar ciertas restricciones a las mujeres, el hecho de que las representantes de dicho modelo sean de alta alcurnia sirve fielmente a tal propósito, pues incluye la advertencia adicional de que ni las de sangre real pueden escapar a tal norma. Queriéndolo o no, el autor de Noticias del Imperio ayuda también a tal propósito desde el comienzo mismo de la obra presentando a Carlota, además de Emperatriz de México y de América, como "Virreina de las provincias del Lombardo-Véneto, [...] hija Leopoldo Príncipe de Sajonia-Coburgo y Rey de Bélgica" (Del Paso, 1994: 9). Ahora bien, el prototipo de mujer enclaustrada para seguir siendo efectivo habría necesitado renovarse con el tiempo; el triunfo de la burguesía en el siglo XIX supuso la incorporación al modelo de otro tipo de locas, el de las adinerada recluidas en mansiones lujosas. Entre ellas se encontrarían por ejemplo Bertha Manson en Jane Eyre (Brontë, 1962 [1847]); Miss Havishan en Great Expectations (Dickens, 1984 [1861]) y Emily Grienson en A Rose for Emily (Faulkner, 1994[1930]), escrita ya en el XX. Con el nacimiento del cinematógrafo se pudo ver también a Norma Desmond en la película Sunset Boulevard (1950) de
W. Wilder, además de adaptaciones de todas las anteriores y grabaciones musicales con personajes como Doña Aurora en el pasodoble Dicen (1967) de Juanita Reina, una especie de versión a la española de Miss Havisham que transcurre en un patio de Sevilla.

Resulta llamativo, que, de las cinco mujeres citadas anteriormente, cuatro de ellas, tras haber sufrido un desengaño amoroso, eligieran la reclusión, al menos en apariencia, de una manera voluntaria, lo cual da a entender que las responsables del daño que se les ha infligido fueran ellas mismas y trataran de pagar por ello. Dicho sentimiento de culpa podría ponerse en relación con uno de los aspectos contenidos en la idea foucaultiana de la sujeción del preso, que es la que tiene que ver con que su cuerpo se presenta siempre como "signo de culpabilidad y transgresión, como encarnación de la prohibición" (Butler, 2001: 96). Esa cursiva de "signo" podría referirse al valor icónico de la imagen de la persona recluida como representación del ideal de sometimiento. La prisión y sus prácticas de reclusión en los casos hasta ahora citados irían dirigidas en primera instancia al cuerpo de estas mujeres. Ahora bien, una vez que las históricas han desaparecido físicamente y que ni a las legendarias ni a las de ficción es posible aplicarle ninguno castigo, dicho signo tendría como objetivo la mirada del espectador o del lector, que asiste a la escena y asume su contenido de una manera pasiva sin oponer ninguna resistencia, lo cual lleva implícito la aceptación de las prácticas de sometimiento femenino como una pauta cultural admisible. Por otra parte, en la teoría psicodrámatica de Rojas-Bermúdez, las formas naturales, es decir, "aquellas en las que hay una capacidad no aprendida que nos permite percibirlas y comprenderlas", entre las que cita la alegría o la pesadumbre, pero donde podrían incluirse también las actitudes pasivas o de sometimiento, tienden por mimesis natural a contagiarse (RojasBermúdez, 2012: 18)

De ser lo anterior cierto, dichas imágenes, en el sentido conceptual se entiende, tendrían dos maneras de impactar sobre la persona que las recibe, una de ellas sería mediante el contagio por mímesis y la otra mediante la asimilación pasiva de las ideas que encierra. Lo que no parece estar en discusión a estas alturas es el poder de la imagen; Foucault empieza Las palabras y las cosas, una obra en la que se reivindica el poder de la palabra, con un análisis en profundidad de una pintura, la de Las meninas de Diego Velázquez (Foucault, 1997: 13). Por ello, no resulta entonces sorprendente tampoco que un estudio psiquiátrico de la demencia de Juana la Loca se abra con otro cuadro del Museo del Prado en lugar de limitarse al cuadro patológico. En este caso el de Francisco Padilla (1887) Doña Juana la Loca ante el féretro de su esposo (1887) para señalar al lector "el mirar lúgubre, la expresión enajenada, los paños y velos negros batidos por el viento de la estepa castellana" de la paciente (Vallejo-Nájera, 1989: 43) Algo que el escritor justifica alegando que esa es la imagen que todos los españoles 
tenemos en la cabeza del personaje desde hace más de cien años, y la elegida por muchos autores para las portadas de sus libros sobre la reina, por ejemplo, en el de Juana of Castile. Histoy and Myth of the Mad Queen (Gómez: 2008), lo cual evidencia lo arraigado de dicha mitología en torno a su relación morbosa con la muerte.

El episodio necrológico de la reina loca de Castilla que no puede separarse del cadáver de su marido, y con el que se ha alimentado su leyenda negra, le ha servido también a del Paso para perfilar la imagen de la de México. Así, varias veces a lo largo de la novela vemos a Carlota hacer referencia a la suerte que siguió el cuerpo del Emperador Maximiliano desde de su fusilamiento en Querétaro, hasta llegar a la Cripta de los Capuchinos en Viena:

Anda Maximiliano, quítate el formol con el que te embalsamaron y ábrete el estómago para que se te salga el aserrín rociado con espliego y la pechuga de pollo que nunca acabaste de digerir. [...] Andale Maximiliano, quitate la esponja empapada en vinos egipcios y sangre de drago con la que te rellenaron la boca y dile a los doctores Alvarado y Montaño que te pongan de nuevo la lengua y la campanilla para que vuelvas a hablar conmigo y me cuentes tus secretos y me digas que me quieres (del Paso, 1994: 236)

Estas elecciones que el autor de Noticias del Imperio y que cualquier otro artista lleva a cabo, bien manera premeditada o inocentemente, a la hora de trazar un modelo de mujer determinado podría relacionarse con lo que Foucault llama "tácticas multiformes de gubernamentalidad" (Varela y Alvarez-Unría, 1991: 18). Éstas prácticas serían aquellos procedimientos de control que el poder, al no estar en condiciones de aplicar en forma de leyes para lograr sus objetivos, utilizará para conseguirlos mediante otros medios, como es la educación, por ejemplo. No hay que olvidar que el poder, además de oprimir a los sujetos, tiene también la misión de formarlos por medio de la interiorización de las normas (Butler, 2001: 30). El prototipo de mujer sometida que se muestra en muchas pinturas, novelas y manuales de Historia parece haberle sido útil al régimen social vigente para mantener unas determinadas creencias en torno a la necesidad de restringir los movimientos de todas ellas en su conjunto. De ser esto cierto, la exposición a las muchas variaciones de dicho modelo puede haber redundado en la fijación de esa imagen y su internalización como parte de los valores aceptables.

En el proceso de asunción de tal creencia desempeña un papel fundamental el leguaje por "el poder que posee para subordinar y excluir a las mujeres" (Butler, 2007: 87); no se trata de que éste pueda ser en sí sexista o no, porque el lenguaje en principio es neutro, sino por las imágenes que pueden evocarse con él al usarlo. En ese sentido, algunos refranes habrían contribuido a asentar y a dar forma a un modelo de muje sometida, por lo cual, éstos desempeñarían un papel auxiliar, pero efectivo, dentro de las estrategias multiformes de gubernamentalidad antes mencionadas que tienen como objetivo situar al género femenino dentro de un espacio cerrado. El refranero español posee una fuerte carga ideológica en todos los asuntos referidos al comportamiento humano y trasmite unas verdades de sabiduría que "nacen en grupos sociales que se oponen a la evolución de la mujer", por lo que en consecuencia "el refrán es el resultado de la autoridad, de la palabra del varón" (Fernández, 1989: 9-10)

Los comportamientos más igualitarios y democráticos de las sociedades modernas pueden hacer que muchas de las afirmaciones contenidas en el refranero suenen anacrónicas. De este modo, el ciudadano actual puede sentir cierto rechazo ante la misoginia explícita contenida en sentencias como "la mujer casada y honrada, la pierna quebrada y en casa, y la doncella, pierna y media" y advertir fácilmente la carga ideológica de "la mujer en casa y el hombre en la plaza". Sin embargo, ese mismo ciudadano, que tildaría tal concepción del género femenino como caduca y que se distanciaría de ella, es posible que al contemplar en la Kunsthalle de Hamburgo el cuadro de Genoveva en la soledad del bosque (1841) pintado por Ludwig Richter pasara inadvertida la ideología implícita en dicha obra.

Por seguir con el espectador antes imaginado, es muy posible que este no acertara tampoco a vislumbrar ninguna relación entre Genoveva y otras maternidades que se desarrollan igualmente dentro de una prisión, y en las que el nacido puede ser considerado la consecuencia más evidente de la conducta desviada de la madre, lo cual la convierte automáticamente en objeto de reprobación. Ejemplos de estas madres las podemos encontrar en la mitología griega con "la enclaustrada Dánae" (García Gual, 1999: 121), pero también en la Historia, pues, aunque la leyenda necrófila de Juana la Loca haya hecho famoso el cuadro antes mencionado de Pradilla, este pintó otro titulado Doña Juana la Loca recluida en Tordesillas con su hija la infanta Catalina (1906) en el que aparece con su hija pequeña.

Es difícil saber en qué medida Fernando del Paso al perfilar la figura de Carlota era consciente de que, al incluir ese aspecto, el de la maternidad prohibida fruto de una relación sexual que se considera inapropiada, estaba contribuyendo a fijar un prototipo de loca, que es reconocible también en otras protagonistas de menos alcurnia, como la galdosiana Fortunata de Galdós, que dio a luz a su hijo en la bohardilla de una casa de "una altura imponente y una estribación formidable, a modo de fortaleza [...] de aspecto lúgubre y monumental, como de castillo de leyendas" (Galdós, 2011 [1887] 202) y de quien se dice, además, que está loca y que "no la sujeta nadie" (Galdós, 2011[1887]:722). En cualquier caso, el dato histórico de la posible maternidad de la reina, ya que hay quien mantiene la tesis de que la razón principal del viaje a Europa de la emperatriz cuando el ejército de Benito Juárez estaba a punto de derrocar a Maximiliano no fue pedirle ayuda a las monarquías europeas, sino recluirse en el 
palacio de Miramar en Italia y dar a luz un niño fruto de una relación con el Coronel Alfred Van Smissen (Haslip, 1971: 506-507), parece haber sido tenido de cuenta a la hora de recrear el personaje literario. Por ese motivo vemos a la protagonista de la novela defenderse de tales acusaciones sesenta años más tarde diciendo que si de alguien va a tener algún hijo, no será "ni de Van der Smissen, ni del Coronel Feliciano Fernández, ni de Léonce Detroyat, ni de nadie", sino de ella "(mí) misma" (del Paso, 1994: 162).

Ese "de mí misma" elimina la posibilidad de una pareja sexual, con lo cual, la única manera que tiene Carlota de conseguir un placer erótico es mediante la masturbación, porque como bien advierte Foucault, desde que el poder se introduce en el cuerpo de los sujetos tratando de dominarlo "emerge inevitablemente la reivindicación del cuerpo contra el poder y del placer contra las normas morales de la sexualidad y el pudor", lo cual a su vez desencadena todos los controles sobre la masturbación que se iniciaron en Europa a partir del siglo XVIII (Foucault, 1978: 104), y de los que la protagonista de la novela no podrá escapar cuando intenta satisfacerse a sí misma eróticamente:

Sentada toda la noche, con las piernas abiertas y el camisón arremangado, me masturbo hora tras hora, sin parar, y la baba que me escurre de las piernas forma un hilo espeso y blanco como tu esperma, Maximiliano, y así me encuentran ellas, y ponen el grito en el cielo y me dicen, qué barbaridad, qué escándalo, una emperatriz jamás debe hacer eso. ¿Una Emperatriz, Maximiliano? ¿De quién dime, soy yo una Emperatriz. (del Paso, 1994: 82).

Dichas semejanzas, y las que se verán más adelante, referidas al modo en cómo se ha venido representado a la serie de mujeres antes citadas, pueden pasar inadvertidas para la mayoría del público que se encuentre con ellas. Lo cual no necesariamente tiene que significar que ciertos detalles pasen desapercibidos por quienes las han contemplado en los cuadros, visto en las películas, o imaginado en las novelas o libros de Historia; se trataría simplemente de que estos detalles no han dejado una huella mnémica. Esto es lo que normalmente se conoce con el nombre de percepción subliminar o supercepción un fenómeno del que se hicieron muchos experimentos en los años 50 del pasado siglo, mediante los cuales se llegó a la conclusión de que "ciertos estímulos que pasan desapercibidos influyen en nuestros perceptos conscientes" (Pinillos, 1979: 206) y, por consiguiente, en la formación de nuestras creencias.

Por seguir con las imágenes icónicas, merece mencionarse que tanto el cuadro de Santa Bárbara de Bayeu (1770), como el de Dánae de Jan Gossaert (1527), por citar dos ejemplos, incluyen como muchos otros la torre en la que fueron recluidas, ya sea como el espacio en el que se ambienta la escena o simplemente como una miniatura formando parte de la composición pictórica. El hecho de que la santa aparezca con el elemento arquitectónico que la hace reconocible es lo esperable desde que sus atributos quedaran fijados en La leyenda dorada en el siglo XIII, cuando Santiago de la Vorágine escribió que la joven Bárbara estaba “dotada de tan extraordinaria hermosa corporal, que su padre, movido por el intensísimo amor que a la hija profesaba, y para evitar que cualquier hombre la viera, hizo construir una altísima torre y la encerró en ella" (de la Vorágine, 1997: 896).

En esa obra de clara intención aleccionadora, además de la de Santa Bárbara, se recoge la vida de ciento ochenta santos y mártires cristianos a los que se representa con ilustraciones impactantes que calaban en la conciencia de un pueblo analfabeto que no sabía leer, pero que podía en cambio interpretar los símbolos.

No es el hecho entonces de que a Santa Bárbara se la muestre siempre con una torre lo que llama la atención, ni que se haga también con Dánae en numerosas ocasiones, puesto que los mismos pintores eran contratados tanto por el clero como por la nobleza laica, y en consecuencia, es de suponer que usaran los mismos modelos. Lo que sí puede suscitar algún interrogante es en qué medida la elección de la misma simbología para ambas mujeres sea casual o tenga su origen en los llamados mitologemas. Estos serían la expresión de la psique colectiva de un pueblo que sigue aflorando en el hombre moderno debido a que aún conservamos un trasfondo mítico en la conciencia (García Gual, 1994: 263). Tales mitos, que perduran a modo de ideas, habrían sido recogidos más tarde por la literatura o plasmados en la pintura. Ello explicaría que tradiciones artísticas distantes entre sí creen en paralelo relatos semejantes para perpetuar valores asumidos por dichas comunidades. En este caso el de la importancia de la virginidad femenina, ya que ambas mujeres son encerradas en una torre para impedir que la pierdan, pues la castidad de ellas resultaba imprescindible para asegurar la línea genealógica masculina tanto en la cultura pagana como en la cristiana.

Del mismo modo que la leyenda de Santa Bárbara y el mito de Dánae ilustran como el modelo de mujer sometida puede coincidir en dos culturas diferentes, igualmente dentro de una misma, este puede aflorar con ciertas variantes sin que ello lo haga menos reconocible, sino que, paradójicamente, servirá para reforzarlo al ampliar el repertorio de los elementos iconográficos con los que una determinada imagen puede ser representada. Así pues, el símbolo de la torre puede sustituirse por el de la gruta rocosa en el cuadro de Ludwig Richter de Genoveva de Brabante, pero también por el del calabozo, "el más horroroso del castillo" (Smichd, 1930:10) en su versión novelada del siglo XIX. De ese modo, las variaciones en el prototipo pueden llegar a darse incluso en un mismo personaje sin que dicha circunstancia afecte al contenido de la información que implícitamente se esté transmitiendo, sino que, por el contrario, contribuirán a afianzarlo.

El caso de Genoveva de Brabante sirve a su vez para ilustrar ciertos controles, mucho más sutiles que las prohibiciones expresas que veíamos emplear antes a las criadas de 
Carlota cuando intentaba masturbase, que se han venido aplicando en nuestra cultura para impedirle a las mujeres procurarse placer erótico. La leyenda de esta noble medieval, transmitida a través de varias versiones, fue posiblemente escrita por primera vez en 1472 por Matthew Emich y está basada en el personaje histórico de María de Brabante (1226-1246), la esposa del Duque Luis II de Baviera condenada a muerte por adúltera (Harty, 2006: 109). Pues bien, la tradición popular, con el visto bueno de la Iglesia, ha conseguido convertirla en una "santa que es motivo de mayor admiración" (Cerisiers, 1733: s/n) y en una esposa casta. De ese modo, la imagen de la mujer como un sujeto con libertad para elegir a sus parejas sexuales queda eliminada en la novela, pero también, según Kevin Harty, de una obra de teatro de L. Teck de 1790 y otra de F. Hebbel de 1847; de las óperas de Haydn (1777), Schuman (1879) y Offenbach (1859); y de tres adaptaciones para la gran pantalla. Así, la verdad histórica termina deviniendo en una obra hagiográfica, en la cual una esposa fiel es encarcelada y abandonada luego en un bosque por negarse a mantener relaciones sexuales con el sirviente a quién el marido la dejo confiada al marcharse a la guerra. Esta versión piadosa es la que recoge en padre Smichd en su novelita Genoveva de Brabante, dirigida principalmente a un público joven, la cual ha seguido editándose, y consecuentemente, transmitiendo dicha concepción de la sexualidad femenina hasta bien entrado el siglo XX.

Sorprende que no sea la historia de la adúltera la que haya pasado a la posteridad, dada la intensidad dramática que la traición y su consiguiente castigo llevan aparejados; fue necesario esperar al siglo XIX para que esposas traidoras como Ana Karenina (Tolstoi, 1977 [1877]), Luisa Mendoza (Eça de Queirós, 1984 [1878]) o Emma Bovary ( Flaubert, 1991 [1856]) tuvieran cabida en la literatura y fueran muriendo poco a poco; dejarlas con vida y a la vista de todos hubiera supuesto una prueba manifiesta de la libertad sexual de la mujer, por lo cual, era preciso deshacerse de sus cuerpos. La triste excepción de Ana Ozores (Clarín, 1983 [1884]) muestra que no hay lugar en este mundo, al menos no lo había a finales del siglo XIX, para una mujer que hubiera buscado el placer sexual fuera del matrimonio. El castigo en este caso fue establecer "un cordón sanitario" en torno a ella al grito de: "! es necesario aislarla!" que pronunció la Vetusta bien pensante (Alas, 1984: 527). Cuando La Regenta, después de romper la promesa de permanecer recluida sin pisar la calle que se había impuesto a sí misma, decide a ir la catedral porque su casa "empezaba a parecerle una cárcel demasiado estrecha" y se desmaya al entrar en el templo, nadie se acerca a levantarla (Alas, 1984: 532-53). Parece evidente que las opciones para la mujer adúltera eran el confinamiento o la muerte, y según Carlota de Bélgica era preferible la segunda, porque "morir, claro, es más fáci que seguir vivo. Estar muerto y cubierto de gloria, es mejor que estar viva y sepultada en el olvido" (del Paso, 1994:10)
El posible adulterio de la Emperatriz y su relación con la locura ya se ha indicado anteriormente que planea sobre la novela y sobre la Historia, pero en el capítulo XXIII la protagonista parece rebelarse contra esos rumores y exclama: “¿Loca yo y puta, sobre todo puta porque el hijo que llevo en las entrañas no lo engendró el emperador de México? No Maximiliano: puta tu cuñada Sisi que tuvo una hija de un cazador de zorras" (del Paso, 1994: 901). A partir de aquí, y con todas las reservas que queramos tener en cuanto a la verdad histórica contenida en el discurso de una loca, Carlota se dedica a hacer una relación de los adulterios cometidos por otras mujeres de sangre real y de los hijos naturales que engendraron. Entre ellas se encuentran la madre de Zar Pablo I; Inés Esteves fundadora de la Casa Ducal de Braganza e Isabel II de España "que si pudo engendrarles como rey para sus súbditos a Alfonso XII fue porque le abrió las piernas y la matriz a un dentista norteamericano, y todos, hasta la mojigata de [mi prima] Victoria, se hicieron de la vista gorda" (del Paso, 1994: 901)

De la afirmación anterior se desprende que el rechazo del adulterio cometido por la mujer sólo sería condenable en el caso de que no fuera ligado a la función reproductiva, que es la que tradicionalmente se le ha asignado a la sexualidad femenina, en tanto que, según Butler, "la proliferación de los placeres fuera de la economía reproductiva implica una forma específicamente femenina de difusión erótica". Es por eso, por lo que, en palabras de la misma autora, cualquier tipo de sexualidad que se desviara de tal fin sería considerada una "contra-estrategia a la construcción reproductiva de la genitalidad" que marca como distintivo la función reproductora de las mujeres (Butler, 2007: 86-87).

En ese esquema de pensamiento, la maternidad solaparía y justificaría de alguna manera el placer erótico que la mujer pudiera obtener derivado de las prácticas necesarias para la fecundación, por lo cual, el retrato que muchas veces se ha hecho de Juana la Loca, como el de una mujer ávida de conseguir placer sexual en su relación matrimonial, podría resultar trasgresor para la sociedad del siglo XVI, cuando las obligaciones de una reina se limitaban a asegurar la continuación de la dinastía; una tarea que Juana había cumplido con creces al darle al marido seis hijos que le sobrevivieron (Gómez, 2008: 136). El cuadro de Pradilla en el que la reina aparece con su hija pequeña, que tan poca importancia tuvo para la continuidad dinástica, puede interpretarse como otra forma de expresar esta misma idea, pero en imágenes. Por usar la terminología de Butler, el deseo de gratificación sexual de Juana desligada de la maternidad podría considerarse como una de esas contra-estrategias a la construcción de la categoría del género femenino.

El control del cuerpo de la mujer por un agente externo implicaría necesariamente ejercerlo sobre su sexualidad. Así, Carlota, al hallarse recluida, el único placer erótico al que parece tener acceso es el de la masturbación, pero cuando sus guardianas le 
prohíben tal práctica no le queda más opción que recurrir a la imaginación y revivir algunas escenas del pasado. Paradójicamente, lo que recuerda son las noches en las que su esposo la dejó abandonada en el Palacio Imperial de México, el Alcázar de Chapultepec, el Albergo di Roma o el Palacio Ducal de Venecia: (del Paso, 1994: 146). Este intento desesperado de la reina por obtener gratificación sexual de su marido y su incapacidad para conseguirlo podrían haber sido un factor determinante en la formación de su patología mental, del mismo modo que lo habría sido para Juana, en quien se aprecia como esa falta de control del cuerpo desempeña un papel determinante en la fabricación de su locura (A. Gómez, 208, 140). La viudez y, por consiguiente, la desaparición del objeto sexual junto con la reclusión y el control que esta lleva aparejada de cualquier otra alternativa sustitutoria del placer erótico no habrían hecho más que empeorar los síntomas de ambas reinas.

Consustancial al tema de la reclusión es el espacio físico donde esta se hace efectiva, ya sea una torre, un palacio, una mansión burguesa o una cueva. Una fotografía del castillo de Bouchout en blanco y negro (Haslip, 1971) muestra una construcción de origen medieval que sigue manteniendo su aire de fortaleza, a pesar de haber sido remodelado más tarde, debido en parte a los torreones circulares que lo flanquean y a una torre cuadrada de veinte metros de altura, la Donjón, del siglo XIV; a ese aspecto de inexorable contribuye el hecho de que se encuentre rodeado de agua. Aun así, este recinto se acondiciona en principio como una residencia campestre destinada a proporcionar un lugar en el que vivir a una reina destronada llegada de México, aunque luego acabe por organizarse siguiendo el esquema de una prisión y un manicomio y persiguiendo sus mismos fines: los de "castigar y resocializar, convertir en inofensivo y curar" (Varela y Álvarez-Unría 1991: 29). La clausura de Carlota en Bouchout, aun sin ser ni un presidio ni una casa de locos, mantendría algunas prácticas propias de ambos, entre otras la del aislamiento, la disciplina, la regulación de los movimientos, el uso del tiempo, el silencio, la confesión y la administración gradual de las penas (Foucault, 1979:229-256) Es a este tipo de prácticas que aquí se aplican sobre una ilustre moradora, las que realizan "el cerco y la invasión completa del cuerpo" en el sentido de que la prisión no solo actúa sobre el cuerpo del preso, sino que "lo hace obligándolo a aproximarse a un ideal, una norma de conducta, un modelo de obediencia" (Butler, 2001: 97). Debido a su doble condición de loca y de reclusa, las guardianas se sienten legitimadas para obligarla a cerrar las piernas e impedir que se masturbe, y la boca para que no le caiga la baba:

¿Qué quieren entonces?, ¿Que además de quieta y callada ni ría ni llore? ¿O sí, que llore yo, y que cuente mis lagrimas antes de beberlas, o que no me la beba, que me escurran también como la baba, y las recoja yo en un dedal, y con los dedales haga yo una torre más alta que la del castillo? ¿O que desbarate yo la torre y derrame los
1994: 83).

Los altos torreones, hemos visto antes, forman parte del imaginario colectivo desde que Dánae fuera confinada en uno de ellos; el coro de Antígona, cuya heroína sufrirá el cautiverio hasta sus últimas consecuencias, recuerda a la audiencia como "también la figura de Dánae [...] encerrada en su cámara sepulcral fue obligada a rendirse" (Vara, 1985: 163). La arquitectura como símbolo amenazante aparece con frecuencia ligado al arquetipo de mujer enclaustrada en general y no solo al de las locas; Juana de Castilla y su abuela Isabel de Portugal parece ser que lo estaban, pero no así su otra nieta Catalina de Aragón que murió confinada en el castillo de Kimbolton (Weir, 2002: 369), igual que su hermana lo haría en Tordesillas y su abuela en Arévalo; Isabel I de Inglaterra, sin llegar a terminar sus días en ella, estuvo confinada en la Torre de Londres, "y aunque sus privaciones físicas no fueron muchas, si lo fueron en cambio las mentales" (Starkey, 2000: 141).

Las palabras anteriores del biógrafo de la reina de Inglaterra confirman que la reclusión, con independencia de las condiciones en que se lleve a cabo, impone una serie de restricciones y que esta es percibida como algo amenazante. Por ello, el hecho de que algunas prisiones fueran en realidad palacios no impide que se las asocie siempre con algo tenebroso, ni que sea con esa apariencia como han pasado a formar parte del imaginario colectivo; en Jane Eyre se da la etimología de "Thornfield", el nombre de la mansión donde vive recluida Bertha Mason, que procede de thorn, espino (Brontë, 1962: 101); la casa de Miss Havisham en Great Expectations se describe como dismal, lúgubre, (Dickens, 1984: 81) y la de Norma Desmond en Sunset Boulevard como de unhapy look y neglected, es decir, con una apariencia triste y abandonada, lo cual, curiosamente, hace que el personaje que la contempla en la película se acuerde de Miss Havisham en ese momento ( Wilder, 1950: Sec. A, 27). Todos estos ejemplos son una evidencia de que el prototipo funciona.

El escenario en el que estas mujeres se nos presentan, ya sea el Castillo de Bouchout o Satis House en Great Expectations, vendría a coincidir con lo que en Psicología se denomina espacio psicodramático, el cual podría entenderse al mismo tiempo como el lugar en las que las reclusas pueden sujetivarse en el sentido foucaultiano de devenir un sujeto, dado que estas necesitan ajustar su estructura mental a su nueva realidad de seres asediados por un poder externo. Esto lo consiguen porque dicho espacio se trata de "una realidad sin tiempo, sin espacio y sin leyes que lo restrinjan; es el espacio de lo posible" en el que se ofrece al individuo la posibilidad de recrear la realidad a su voluntad y transformarla (Rojas-Bermúdez, 1977: 24). En la novela de Fernando del Paso se ve como la protagonista en su locura se puede permitir prescindir de esa coordenada temporal cuando ordena que todos los relojes del castillo estén detenidos 
para siempre a las siete de la mañana, la hora en la que murió su marido en el Cerro de las Campanas (del Paso, 1994: 319). Esa prerrogativa se la arroga también Miss Havisham en Great Expectations cuando manda detener los relojes justo a la hora en la que llegó la noticia de que su prometido no lo haría para la boda; el momento en el que ella decide convertirse en una eterna novia, sin tiempo, y por lo cual no volverá a quitarse su traje nupcial.

El paralelismo que se acaba de señalar entre Miss Havisham y Carlota de México para mostrar que la misma situación de clausura que las sujeta es la que les permite al mismo tiempo reinventarse como sujeto, deja entrever igualmente que ambas parecen responder a un mismo modelo preestablecido que se va repitiendo. La traducción de tal afirmación en términos psicodramáticos sería que la prisión proporciona a la mujer recluida el escenario donde construir una nueva imagen de sí misma como ser cercado, pero lo hace limitando los materiales que pone a su alcance. En el caso de Noticias del Imperio parece que el autor ha concentrado en su protagonista casi todos los atributos del modelo que se han venido señalando. Carlota representa a la perfección ese prototipo de reina loca difundido en la tradición cultural de Occidente, el cual ha sido recogido por el también mexicano Carlos Fuentes en su personaje la Dama Loca de Terra Nostra (1975) que tanto recuerda a la Juana de Castilla y que encarnaría a varias reinas españolas al mismo tiempo (Williams, 1997: 425); pero es esa ausencia de nombre la que habría contribuido a que el modelo se universalice y sirva para incluir en él a todas las mujeres sobre las que de manera general el poder, aunque sea de forma más sutil, ejerce una serie de controles, que son en los que, según denuncia Judith Butler, se encontrarían las causas del sometimiento femenino, y los que convierten a quienes lo sufren en la loca de la casa.

$\mathrm{Y}$ ya para concluir, y no seguir dando vueltas en círculo como las locas, mencionar solamente que así abre la novela Noticias del Imperio Fernando del Paso: "La imaginación, la loca de la casa - Frase atribuida a Malebranche -" (del Paso, 1994: 9).

\section{REFERENCIAS BIBLIOGRÁficAs}

Alas, L. (CLARÍN), La Regenta, Madrid, Castalia, 1983.

Brontë, C., Jane Eyre, Middlesex, Penguin Books Ltd, 1962.

Butler, J., Mecanismos psíquicos del poder. Teorías sobre la subordinación, Madrid Ediciones Cátedra, Madrid. 2001.

----, El Género en Disputa. Paidós: Barcelona, Paidós, 2007.

Ceseriers, S., Vida de Santa Genoveva Princesa de Brabante, Madrid, A costa de Pedro Joseph Antonio y Padilla, 1733.

Dickens, C., Great Expectations, Middlesex Penguin Books Ltd: Harmondsworth, 1984.
Eça de Queirós, J. M., El primo Basilio. Madrid, Alianza Editorial, 2004.

Fernández, M., Refranero español. Antología de refranes populares y cultos de la lengua castellana explicados y comentados. Madrid, Editorial Burdeos, 1989.

Faulkner, W., A Rose for Emily, Princeton, Merril Publishing Company, 1970

Flaubert, G., Madame Bovary. Madrid, Austral, 1991.

Foucault, M., Microfísica del poder, Madrid, Las ediciones de la Piqueta, 1978

----, Las palabras y las cosas: una arqueología de las ciencias humanas, Madrid, Siglo XXI, 1997.

----, Discipline and Punish, New York, Vintage Books, 1979.

Fuentes, C., Terra Nostra. Madrid, Espasa Calpe, 1991.

García Gual, C., Introducción a la mitología griega. Madrid, Alianza Editorial, 1999.

Gómez, M., Woman, Nation, and Desire in Juan de Orduña's Locura de amor and Vicente Aranda's Juana la Loca, Grabury, Associated University Presses, 2008.

Grecia, M. de, La emperatriz del adiós, Barcelona, Editorial Plaza y Janés, 2000.

Haslip, J., The Crown of Mexico. Maximilian and His Empress Carlota, Chicago, Holt, 1971.

Harty, K., The Reel Middle Ages American, Western, Eastern and Asian Films about Medieval Europe, Jefferson, N.C. McFarland \& Company, Inc. Publisher, 2006.

Job, B., Charlotte l'impératrice d'outre-mer, Oxford, Oxford University Press, 2004.

Navarro García, L., Historia de las Américas, Sevilla, Secretaría de Publicaciones U. S, 1991.

Paso, F. del, Noticias del Imperio, Barcelona, Plaza y Janés, 1994.

Pérez Galdós, B., Fortunata y Jacinta, Madrid, Cátedra, 2001.

Pinillos, J. L., Principios de psicología. Madrid, Alianza universidad, 1979.

Reina, J., Dicen, Madrid, Discos Belter, 1967.

Rodríguez y otros, Historia de España. La España de los Reyes Católicos (Tomo 5), Madrid, Espasa Calpe, 2004.

Rojas-Bermúdez, J. (Coord.), Teoría y técnica sicodramática, Barcelona, Paidós, 1977.

----, Actualizaciones en sicodrama, A Coruña, Espiralia Ensayo, 2012.

Smichd, C., Genoveva de Brabante, Barcelona, Ed. Ramón Sopena, 1930.

Starkey, D., Elizabeth, Surrey, Vintage, 2001.

Tolstoi, L. Ana Karenina. México, Bruguera, 1977

Vallejo-Nájera, J. A., Locos egregios, Barcelona, Planeta, 1989.

Vara, D., Sófocles. Tragedias completas. Madrid, Cátedra, 1985.

Varela y Álvarez-Unría. Espacios de Poder. Madrid, Las ediciones de la Piqueta, 1991.

Vorágine, S. de la, La leyenda Dorada, Madrid, Alianza Forma, 1997.

Wilder, W., Sunset Boulevard. Paramount Pictures, 1950. 
Williams, R., “Terra Nostra y el Escorial: una lectura”, Thesaurus: Boletín del Instituto Caro y Cuervo. Tomo 52. (1997).

Weir, A., Henry VIII. King and Court. London, Plimpico, 2002. 